\title{
A PRESENÇA DO SAGRADO NA LITERATURA EDUCACIONAL. RESSONÂNCIAS DA CRIANÇA DIVINA NO PENSAMENTO DE MARIA MONTESSORI ${ }^{1}$
}

\author{
Alberto Filipe Ribeiro de Abreu Araújo* \\ José Augusto Lopes Ribeiro**
}

\begin{abstract}
RESUMO
O sagrado no pensamento educacional de Maria Montessori e as ressonâncias da criança divina. Trata-se numa primeira parte da relação entre a educação e o sagrado na perspetiva de Olivier Reboul. Numa segunda parte focar-se-á o lugar de Maria Montessori no seio da Educação Nova, bem como se expressa a sua concepção de "criança nova". Finalmente, e já numa terceira parte, fala-se da ressurgência da Criança Divina na obra da autora como prolegómenos de uma religião da infância.
\end{abstract}

Palavras-chave: Sagrado. Maria Montessori. Criança divina. Religião da infância.

\begin{abstract}
The sacred in the educational thought of Maria Montessori and the resonances of the divine child. The first part of the article focuses on the relation between education and sacred, in the eyes of Olivier Reboul; the second part focuses on the place of Maria Montessori in the movement of New Education and her concept of "divine child". Finally, in a third part, the reappearance of the Divine Child in the work of the author is underlined, connecting it to the emergence of a childhood religion.
\end{abstract}

Keywords: Sacred. Maria Montessori. Divine child. Childhood religion.

\footnotetext{
* Professor Doutor em Educação no Departamento de Teoria da Educação e Educação Artística e Física do Instituto de Educação (IE) da Universidade do Minho (UM) Braga Portugal. Correio eletrónico: afaraujo@ie.uminho.pt

** Mestre em Ciências da Educação na área de especialização em Desenvolvimento Curricular pelo Instituto de Educação da Universidade do Minho (Braga - Portugal). Atualmente é Professor de Filosofia do Ensino Médio na Escola Secundária Sá de Miranda (Braga - Portugal). Correio eletrónico: jauribeiro@gmail.com

1 Este trabalho é financiado por Fundos Nacionais através da FOT - Fundação para a Ciência e a Tecnologia no âmbito do Projeto PEST-OE/CED/UI1661/2014.
} 
"A criança é religiosa porque é criança" (REBOUL, 1992, p. 232.)

“É a criança nova que, só, nos pode conduzir e mostrar-nos o nosso caminho"

\section{Introdução}

(MONTESSORI, 1931, p. 110.)

A proposta pedagógica de Maria Montessori (1870-1952) inscreve-se simultaneamente na abordagem cientifizante da pedagogia dotada de um método inovador (), e mitopoética de cariz cristão e católico da infância (KILPATRICK, 1914; KRAMER, 1976; BERTINI, 1953; BIANCHI, 1952; LEONARDUZZI, 1967; PERETTI, 1952; SARTOR, 1961; STANDING, 1995; VALITTUTI, 1953; YAGLIS, 1984; LILLARD, 1972; MONTESSORI, 2004 ab; RÖHRS, 2010). Ela reflete, nas palavras de Daniel Hameline, um "halo de religiosidade humanista e cósmica" (HAMELINE, 2000, p. 52) que consagra a criança como um ser espiritual - "um embrião espiritual" diz a autora - e de natureza divina. A este idealismo espiritualista, que consagra a criança como um ser espiritual e de natureza divina, não é indiferente a sua formação católica, pelo que ela inscreve todo o seu pensamento educacional na corrente humanista cristã, diríamos mesmo de forte inspiração personalista. Os seus escritos psicopedagógicos não podem deixar de refletir a sua formação acadêmica e católica, bem como as figuras mais pregnantes simbolicamente do seu imaginário individual. A este propósito, não deixa realmente de surpreender que no seu discurso psicopedagógico de cariz científico se encontre com muita frequência citações bíblicas e referências explícitas ao Messias e a Cristo (BÖHM, 1994, p. 155-157; STANDING, 1995, p. 48; GRÁCIO, 1973, p. 175; AVANZINI, 2004, p. 141).

Antes de enunciarmos o plano do presente estudo, importa salientar que entendemos por literatura educacional todo aquele gênero literário que se ocupa da formação do ser humano no sentido que os alemães conferem à noção de "Bildung" que se opõe à educação formal (Erziehung). Um exemplo acabado deste gênero é o "romance de formação" (Bildungsroman) 
materializado, por exemplo, no Wilhelm Meisters Lehrjahre (Os anos de aprendizagem de Wilhelm Meister) de Goethe (1795-96).

Dedicaremos a primeira parte deste estudo à educação e sagrado onde destacaremos o contributo de Olivier Reboul; numa segunda parte realçaremos o lugar da autora no movimento da educação nova e falaremos da sua conceção de criança como pai e mestre da Humanidade, visto que ela enfatiza a ideia de "criança nova" como construtora de uma "mundo novo". Na nossa terceira parte - A ressurgência da Criança Divina no pensamento educacional de Maria Montessori - enfatiza-se a condição de inocência da criança que vem a ser Messias redentor e as suas ressonâncias míticas, porque para a pedagoga italiana a sociedade deve ser reconstruída, e a criança possui a potencialidade que, combinada com um ambiente estimulante, ajudará a formar um "homem novo" para um "mundo novo". Também nesta última parte, esboçaremos um pequeno contributo de uma religião da infância baseado na obra montessoriana.

\section{Educação e sagrado}

Olivier Reboul foi o primeiro filósofo da educação, senão mesmo o único, a tratar explicitamente da relação entre o sagrado e a educação (REBOUL, 1990, p. 112-117, REBOUL, 1992, p. 221-240). O autor considera que "não há educação sem um certo sagrado" completa o seu axioma "que não há educação sem valores" (REBOUL, 1990, p. 112). Importa desde já salientar que a presença do sagrado na consciência dos homens carateriza-se simultaneamente pelo sacrifício e pelo sacrilégio (REBOUL, 1990, p. 114; REBOUL, 1992, p. 225-226), assim como o sagrado é um viveiro de símbolos e aqueles que realmente o são não podem deixar de ser sagrados, tal como Paul Ricoeur, Mircea Eliade, Gilbert Durand Jean-Jacques Wunenburger nos ensinaram (RICOEUR, 2002, p. 167-306; ELIADE, s.d., p. 171-220; ELIADE, 1977, p. 65-547; DURAND, 2008, p. 219-272; WUNENBURGER, 2009, p. 22-43).

À questão se todos os valores são sagrados, o autor responde que não, pois há os profanos que são os valores técnicos, utilitários e 
econômicos determinados pelo critério da eficácia como valor absoluto. Estando o homem moderno mergulhado na sua mundividência laica, prometeica, senão mesmo fáustica, não é algo que admire que a sua relação com a esfera do sagrado seja no mínimo conflitual caso se considere que o universo do sagrado compreende aquilo que a razão agnóstica e positivista considera irracional, misticismo dogmático, mistério fascinante e tremendo, sacrificial, expiação coletiva, tabu, puro-impuro e a vida no além seja ela no céu ou no inferno (REBOUL, 2009, p. 59-80). Por oposição a este tipo de valores, que não consideramos valores da educação (REBOUL, 1992, p. 4-5, REBOUL, 1191, p. 197-202), existem aqueles considerados pela filosofia da educação como valores e que importam à educação (REBOUL, 1992, p. 4):

Os valores da educação concernem o sentido, mais precisamente tudo aquilo que permite a cada criança humana aprender a tornar-se homem. [...] Os valores da educação estão ligados ao aprender [a ser]. Eles são aquilo que merece ser aprendido por cada um [...]; aprender sendo tornar-se homem (REBOUL, 1992, p. 5-9).

Como já deixamos atrás antever, o desencantamento do mundo, a desmitologização e a dessacralização (WUNENBURGER, 2009, p. 89105) que a acompanha não conseguem erradicar o sagrado da educação, porquanto quando se fala de valores, e se fazem juízos de valor, o sagrado nunca anda longe: "o sagrado induz modos de agir seletivos, determinando assim normas morais. Na volta, o sagrado participa da vocação e da legitimação ética" (WUNENBURGER, 2009, p. 117). A educação, que se pretende racional e que simboliza o profano, mais do que eliminar cegamente o sentimento do sagrado que decorre dos valores deve, pelo contrário, purificá-lo e dignificá-lo.

\subsection{Sobre a criança divina}

A Criança Divina é para nós sinônimo do "deus-criança” e retoma na perspetiva junguiana os traços gerais do arquétipo da criança, tal como eles serão descritos mais à frente. Ela constitui um dos núcleos mais perenes 
do imaginário humano dado a sua forte e íntima simbiose com os mitos fundadores da nossa civilização. Por outras palavras, e para recordarmos aqui Gaston Bachelard, a infância representa a permanência imóbil na alma humana e fora da história (BACHELARD, 1974, p. 85; DURAND, 1979a, p. 84-87). É assim que se entende que a criança, à semelhança da natureza do mito, represente simultaneamente um desafio e uma negação da visão positivista, racionalista e etnocêntrica da vida e do mundo. Para caraterizar a essência divina da Criança e da Infância numa existência intemporal, aquela que é própria aos deuses, lembremos as palavras de Homero quando ele se refere aos deuses gregos: eles não envelhecem, eles não morrem, eles são eternos. De acordo com Karl Kerényi, o retrato clássico da infância de um deus, tendo em conta o hino homérico de Hermes, nos é dado precisamente por este deus: o deus celebrado é uma criança:

a infância de um deus não significa de modo algum que ele tivesse um poder reduzido ou uma menor importância. Pelo contrário, quando uma divindade aparece no meio de outros deuses sob forma de criança, é a sua epifania que se encontra no centro da situação ou, para nos exprimirmos mais claramente, a epifania é sempre a da criança divina (KERÉNYI, 1974, p. 80).

Toda a criança que nasce é já uma figura encarnada da origem que, por conseguinte, reatualiza quer a origem do mundo, o tempo antes da "Queda", a inocência primigênia, bem como o futuro de uma humanidade redentarizada: "é talvez por que ela traz consigo o mistério da vida nascente que a criança é mítica por essência” (WALTER, 2002, p. 3). A Criança Divina, enquanto figura iniciática e messiânica poderosa, possui, entre outros, os seguintes atributos: ela é mediadora, ela é profeta, ela é visionária, ela conhece os segredos do mundo. Esta Criança representa a plenitude de vida de que a figura da criança prodigiosa está imbuída: ela é o protótipo, o modelo arquetipal da criança original que Jung nos fala (JUNG, 1974, p. 105-144). Os seus traços mais significativos são nos fornecidos por um conjunto de mitologemas estudado por Kerényi: orfandade, abandono, solidão, fraqueza e força: 
A presença de amas divinas ou de animais amamentadores no mito de Zeus, - e a imitação destas amas no mito de Dionísio criança exprime duas coisas: o estado solitário da criança divina, e o facto que, apesar de tudo, ela encontra-se no mundo original. É uma situação de dupla face: a de um órfão, e ao mesmo tempo a de uma criança amada pelos deuses (KERÉNYI, 1974, p. 47).

Do seu lado, Jung classifica a criança que, como elemento "mitogénico", aparece no psiquismo inconsciente, ao que ele dá o nome de "inconsciente coletivo", na categoria dos "temas" (Motive), "imagens primordiais" (Urbilder), "tipos" (Typen) e de "arquétipos" (Archetypen): "O tema da criança é representativo do aspeto infantil pré-consciente da alma coletiva" (JUNG, 1974, p. 118). Assim, a criança prototípica, que se faz tantas vezes acompanhar dos seus símbolos (joia, pérola, flor, vaso, ovo de ouro, bola de ouro, etc.) define-se pela polarização arquetipal: insignificante-significante; pequena-grande; passado-presente-futuro; angélica-demoníaca; solidão-cosmicidade; unidade-pluralidade; abandonoinvencibilidade, ocultação-exposição; ser inicial-ser final (JUNG, 1974, p. 126-141). Destes atributos, Jung atribui uma importância particular à dimensão do futuro que a criança representa: "A criança é o futuro em potência" (JUNG, 1974, p. 122). Ele é o mediador e o salvador é uma espécie de proto-símbolo unificador de contrastes de polos opostos, daí Jung falar do hermafroditismo da criança: "O hermafroditismo não significa outra coisa que a reunião dos contrastes mais fortes e mais significativos" (JUNG, 1974, p. 134). Aliás, este aspeto confirma a justeza do axioma jungiano que diz que o arquétipo "se apresenta como um mediador que reúne os contrastes entre as bases inconscientes e o consciente. Ele lança uma ponte entre a 'consciência do presente', ameaçada de dissolução, e o Todo próximo da natureza, inconsciente e instintivo, das épocas passadas" (JUNG, 1974, p. 136).

$\mathrm{O}$ mitologema da criança original, que serve de modelo à Criança Divina, é inseparável da água original (o mar). O mar que simboliza a fonte da água primeira representa o corpo maternal, o seu seio e o berço que acolhe todo o ser vivo: veja-se o exemplo emblemático da criança montada num golfinho. A Criança Divina que mais aparece ligada ao mar é Dionísio, aspeto aliás realçado por Karl Kerényi (1974, p. 99-100), que à semelhança de Hermes, representa também o retrato da Criança Divina original: 
As águas infinitas estão também organicamente ligadas à imagem da criança original como o corpo maternal está ligado ao seio. [...] $\mathrm{O}$ tema original é o mesmo em Creta que no Continente: é o da aparição da criança original num lugar pertencendo ao mundo da origem, colocado em correlação com os elementos maternais originais: os rochedos e a água (KERÉNYI, 1974, p. 77-94).

Por fim, o filosofema que parece melhor corresponder ao mitologema da Criança Divina nos é dado pelo próprio Kerényi e representa um estado peculiar mediatizado pelas figuras divinas de jovens: "não ser ainda eliminado do não-ser e no entanto já sê-lo" que pode também assim ser descrito: "não sendo ainda eliminado da existência e no entanto não ser” (KERÉNYI, 1974, p. 102-103).

\section{Maria Montessori e a educação nova}

O movimento da educação nova ergueu, como seu estandarte principal, a máxima que a infância existe para si e por si própria. Esta máxima gira em torno das seguintes ideias-força, entre outras, a saber: da herança roussauneana que refere que a "criança existe enquanto tal e para ele crescer é preciso respeitar a sua natureza"; do Discat a puero magister - que o mestre aprenda com o seu aluno - que é, aliás, a divisa do Instituto Jean-Jacques Rousseau, fundado por Edouard Claparède em Genève (1912); do adágio de Píndaro, que diz "Torna-te naquilo que és" que Montessori estimulava pelos momentos de silêncio em que as crianças aprendiam a concentrar-se, a autoconhecerem-se e a acederem à paz interior; trazer a vida para dentro da escola e o inverso de acordo com a fórmula tão querida a Ovide Décroly que defendia que a escola devia "preparar a criança para a vida, pela vida" (ARAÚJO, 2004, p. 33-40), e finalmente do tema da "emancipação da infância" que desempenha um papel crucial no ideário educacional e pedagógico dos inovadores da Educação Nova. Estas "imagens falantes" (Hameline) ilustram bem o pulsar ideológico da educação nova e que a educadora e escritora Ellen Key bem soube intuir na sua obra $O$ século da criança (1900), e que Maria Montessori ao longo da sua vida não deixou de lhe fazer justiça quer pela sua ação pedagógica, quer pela edição das suas obras e realização internacional de conferências. 
Mas o que é que na verdade a educação nova possui, qual o seu charme e encanto mágicos? Contentemo-nos tão somente de, na companhia de Olivier Reboul, de citar algumas das suas principais caraterísticas:

O seu princípio fundamental é o retorno à criança, sujeito de pleno direito da sua própria educação; esta deve portanto inspirar-se na sua vivência e nas suas necessidades, em vez de lhe impor de objetivos distantes. É uma escola ativa em que a criança, em vez de escutar e de imitar, aprende por si mesma, escolhendo dentro do possível aquilo que ela aprende, assim como as maneiras como aprende. É uma escola cooperativa em que as grandes decisões são tomadas em comum pelos conselhos de alunos e em que se pratica, sempre que possível, trabalhos coletivos próximos da vida: jornal da sala de aula, cooperativa escolar, espetáculos... Enfim, é uma escola democrática que quer dar a todos uma verdadeira oportunidade de sucesso. A força da Educação nova reside na sua pedagogia (não haveria sem dúvida pedagogia sem ela!) (REBOUL, 1992, p. 9-10).

Maria Montessori mesmo se ela atribui uma grande importância à espontaneidade da criança e ao papel da natureza, não deixa contudo de encarar com algum ceticismo o mito romântico de uma infância livre e feliz no seu estado de natureza, com os valores libertários que lhe estavam associados, na perspetiva de Jean-Jacques Rousseau, e que fazia da Natureza o livro e a guia da educação de Emílio enquanto aluno ideal (BOSETTI, 1997, p. 19-54). Aquilo que a pedagoga italiana insiste é sobre o conhecimento da personalidade infantil; da necessidade da criança aprender a ser autônoma fisicamente, sensorialmente, intelectualmente, manualmente ou socialmente e que se pode sintetizar na famosa divisa "Ajuda-me a agir sozinho" (MONTESSORI, 1931, p. 106); da liberdade da criança como contraponto à rigidez e à disciplina artificial da educação tradicional e, muito especialmente, insiste na necessidade da educação ser realmente uma "ajuda para a vida" porquanto Montessori defende que devemos educar a criança não para o mundo atual, isto é, para a vida de hoje, dado que este mundo será já outro, e não há ninguém que possa adivinhar como ele será, quando a criança for adulta, então aquilo que é mais urgente é ensiná-la a adaptar-se (MEIRIEU, 2001, p. 14-22): 
A educação não deve ser mais e principalmente transmissão de conhecimentos; é preciso que ela se oriente numa nova direção, que ela procure desenvolver as potencialidades humanas. [...] É aqui que começa uma nova orientação na qual não será mais o professor que ensina a criança, mas a criança que ensina o professor (MONTESSORI, 2010, p. 8-9).

Deixar a criança livre e estudar a formação da sua personalidade, eis "os dois pivôs sobre os quais gravita a pedagogia moderna" (MONTESSORI, 1931, p. 102).

Num registo hipotextual não deixa explicitamente de venerar o culto do Menino Jesus e o tema da Criança Rei reativado na Itália católica, especialmente a partir da I Guerra Mundial. Defendia igualmente as virtudes teologais da infância o que consubstancia uma fé na infância, além de tornar o Menino Jesus, enquanto Criança salvadora da Santa Família, um modelo exemplar, mesmo arquetipal (BOSETTI, 1997, p. 69-125). A criança consagra-se, do ponto de vista ético, um modelo de comportamento:

Neste mito romântico e/ou cristão, ela [a criança] não é somente objeto de admiração ou de adoração e de veneração, mas sujeito; um sujeito que a visão mágica ou a imaginação fervente magnifica a criação, idealiza os seus próximos e diviniza os seus parentes. Ela é ao mesmo tempo mitificada e mitificante. Os romancistas exploraram naturalmente esta virtude mitopoética (BOSETTI, 1997, p. 148).

Neste contexto, não é surpreendente que o ideário educacional montessoriano seja caraterizado por uma confiança absoluta nos poderes e capacidades da criança, pela divinização da natureza infantil e culto, de tipo religioso, da sua personalidade e das suas tendências (BLOCH, 1973). Mais concretamente, a Criança Nova aparece como uma espécie de "criança prodígio" porque possuidora de um grande poder, "fonte de amor", "embrião espiritual" e dotada de uma "mente absorvente " que lhe permite adaptar-se à vida e ao mundo: "A criança suporta tudo: entra no mundo, em qualquer ambiente que nasça, aí se forma e se adapta a viver, e o adulto que será um dia, será feliz naquele ambiente" (MONTESSORI, 1971, p. 340). 
Maria Montessori tinha o sonho de formar (no sentido de desenvolver as potencialidades de cada criança) uma "criança nova" mediante uma educação ativa que respeitasse os interesses naturais da criança. Procurava, assim, construir graças à "criança nova", anunciadora do homem de amanhã, um "mundo novo" correlato de uma sociedade pacífica: "Um mundo novo para um homem novo, é a nossa necessidade mais urgente" (1996, p. 44). A necessidade de se formar um "homem novo" para um "mundo novo" tem a ver com o horror da I Guerra Mundial que destruiu, qual vaga vulcânica, tudo aquilo que encontrou à sua frente e que teve fortes repercussões em toda a Europa e obviamente em Itália onde igualmente se deve acrescentar a ditadura de Mussolini (BOSETTI, 1987, p. 292-303). Daí que Montessori seja uma intransigente defensora da paz e que veja na educação e na religião católica instrumentos ao serviço da reconstrução de uma Europa destroçada e, consequentemente, da "construção de uma sociedade pacífica e harmoniosa que eliminará a guerra” (MONTESSORI, 2010, p. 7).

Para que o desígnio de um "mundo novo" seja realizado torna-se necessária uma educação nova que rompa com os métodos da educação tradicional, nomeadamente com a transmissão do saber, a disciplina rígida na sala de aula e a avaliação feita na base ritual dos exames. Para isso, a autora propõe uma investigação científica sobre a personalidade humana, particularmente da criança, baseada numa pedagogia científica e numa nova orientação que a "criança nova" se encarregará de indicar ao educador e ao mundo da educação: "é a figura da criança nova: revelação, poder-se-ia dizer descoberta psicológica que guia a educação nova" (MONTESSSORI, 1931, p. 105). A "criança nova", de acordo com Maria Montessori, apresenta de per se, ainda que não saibamos muito bem qual é o fundamente psicopedagógico que lhe permite avançar com esta descrição, um conjunto de qualidades que supostamente a criação de um meio adequado deveria suscitar e formar de forma qua as melhores qualidades da criança fossem despertadas, a saber: "a disciplina, a ordem, o silêncio, a obediência, a sensibilidade moral, resumindo tudo aquilo que denota um poder de adaptação muito pronunciado" (MONTESSORI, 1931, p. 106).

Mas de que modo a criança assume um estatuto quase divino, de herói e de salvador? A resposta advém do poder que a "nova educação" possui em ajudar a criança a desenvolver plenamente as suas potencialidades 
de modo a que ela se torne cada vez mais autônoma. O mundo psíquico da criança é dotado de poderes psíquicos especiais e possui uma energia construtiva, viva e dinâmica graças àquilo que Montessori designou de "espírito absorvente" que significa que ela absorve o saber e se instrui por si própria (MONTESSORI, 2010, p. 27-35). É portanto esta constatação que conduz a autora a afirmar que a educação não é aquela que o mestre dá, pois esta "é um processo natural que se desenvolve espontaneamente no indivíduo humano e se adquire, não escutando as palavras, mas fazendo experiências no meio" (MONTESSORI, 2010, p. 10). Aquilo que o mestre pode fazer, é criar as condições propícias, e abster-se de ser diretivo para que a criança possa, por si própria, desenvolver as experiências de aprendizagem necessárias ao seu desenvolvimento psíquico: “Agindo assim [os mestres humanos] serão as testemunhas do desenvolvimento da alma humana e do nascimento do Homem Novo, que não será mais a vítima dos acontecimentos mas terá uma visão cara para dirigir e modelar a sociedade humana de amanha" (MONTESSORI, 2010, p. 10-11).

Essesonho, aliáscomumaomovimentodaeducaçãonova, depositava na nova educação uma fé sem limites, em vista à salvação e à redenção do futuro homem, assim como apostava, mediante a educação, em regenerar a sociedade: "A escola é o instrumento da renovação social. A escola é o instrumento da construção do novo mundo. A escola é o instrumento da preparação do futuro melhor para a humanidade" (HOUSSAYE, 1996, p. 59). Esta crença, que não pode nem deve ser dissociada de um projeto sociopolítico e dos seus respetivos envolvimentos ideológicos, não é senão a crença na "perfectibilidade indefinida do homem" associada, por sua vez, à crença na ideia de "progresso" também ele indefinido (MONTESSORI, 1996, p. 60-62). A educação nova, como contraponto ao figurino do aluno saído da escola tradicional, tinha como seu principal objetivo formar uma "criança nova" num quadro pautado pelo espiritualismo, psicologismo e individualismo (MIALARET, 1976, p. 12-13). Se este quadro for completado pela tradição humanista progressista, pela cientificidade da pedagogia (ciência psicológica e o movimento da pedagogia experimental) e pelos 30 pontos da escola nova, que foram publicados pela primeira vez, como é conhecido, na obra de Faria de Vasconcelos, intitulada Une école nouvelle en Belgique (1915) (NÓVOA, 1995, p. 32-34), cremos ter 
estabelecido, ainda que resumidamente, os contornos da educação nova (BLOCH, 1973; MIALARET, 1969; OHAYON, OTTAVI \& SAVOYE, 2004). O aluno ideal a formar pelo movimento da educação nova deveria não só ser orientado e influenciado por este novo credo, como também aproximar-se, quanto possível, do figurino de uma "criança escolarizada, ativa, autónoma, solidária e engenhosa na construção do seu próprio saber" (HAMELINE, 2000, p. 52).

Neste contexto, a criança, encarnando a natureza humana pura e não deformada, está mais próxima de Deus que o próprio adulto e daí deve ser ela a guia e a construtora do "homem novo". Assim, a criança, na qualidade de construtora do homem, deve ser objeto de uma educação que baseie a sua ação no "desenvolvimento da personalidade humana" (MONTESSORI, 1971, p. 16). Por outras palavras, cabe à nova atitude educativa fazer do desenvolvimento das potencialidades humanas o seu principal objetivo e evitar que o professor comprometa, com as suas intervenções inoportunas e desadequadas, que a aprendizagem da criança se faça num ambiente recetivo (MONTESSORI, 1971, p. 15; BÖHM, 1994, p. 157-159; RÖHRS, 1995, p. 175-178).

Somente uma criança livre, com uma personalidade adaptada a um meio-ambiente e estimulante ao seu desenvolvimento, poderá construir o Homem Novo anunciador de um "futuro luminoso" e de um " mundo novo". Toda a educação, na ótica de Maria Montessori, deve ser uma "educação para a vida" (MONTESSORI, 1971, p. 17-26), pois para ela aquilo que está em causa é a construção, e não a reconstrução, da "mente da criança": "construção entendida como desenvolvimento de todas as imensas potencialidades de que a criança, filha do homem, é dotada" (MONTESSORI, 1971, p. 26). Na sua Formação do homem (1949) estabelece qual o objetivo da nova educação. Assim, esta não é somente um problema escolar ou de simples metodologia educativa, mas antes antropológico, ou seja, existencial e aqui existencial é sinônimo de "libertação universal". Montessori defende o papel da psicopedagogia que não é mais do que a psicologia aplicada à educação. A psicopedagogia deve "ajudar a vida" que começa com o recém-nascido e termina no adulto. Por isso mesmo é que a autora fala de que "o nosso primeiro mestre será a própria criança” MONTESSORI (s.d., [1949], MONTESSORI, 
s.d. [1936], p. 288-291), devendo o adulto, nomeadamente a professora montessoriana, inspirar-se no próprio comportamento da criança enquanto "mestre da vida", construtora e guia da humanidade (MOMTESSORI, s.d. [1936], p. 290-291).

A criança, por tudo aquilo que já se disse, não é concebida como um adulto em miniatura, pois ela possui uma vida pessoal com as suas características e um fim específicos. A vocação da criança, lembra-nos Maria Montessori, é a de encarnar a personalidade humana e esta, por sua vez, deverá ser uma personalidade capaz de construir um homem adaptado quer ao seu ambiente, quer ao seu tempo. Assim, a nova educação, concebida como uma "ajuda à vida", devia, por um lado, estar atenta ao desenvolvimento de todos os aspetos do ser humano (físico, intelectual, emocional e espiritual) e, por outro lado, formar um "Homem Novo" de modo a que ele não seja mais a "vítima dos acontecimentos", mas que tenha "a clareza de visão necessária para dirigir e plasmar o futuro da sociedade humana” (MONTESSORI, 2000, p. 14).

\section{A ressurgência da criança divina no pensamento educacional de Maria Montessori}

O retorno do tema da Criança Divina no seio da ideologia educacional dá que pensar dos pontos de vista da relação ideologia-mito (SIRONNEAU, 2005, p. 183-192) e do retorno do religioso, ainda que revestindo mais uma vocação ética do que religiosa propriamente dita, mesmo que a vida de Cristo e os ensinamentos que dela decorrem sejam dados como exemplo. Em última instância, encontramos de novo aqui a incontornável relação entre mito e sagrado acompanhada dos seus ritos próprios.

\subsection{A criança divina na obra educacional de Montessori}

A criança divina na obra psicopedagógica da autora está fortemente influenciada pela vida de Jesus e, muito particularmente, pelo culto do Menino Jesus enquanto Criança-Deus que ultrapassa, para se situar num plano já ontológico, o mero "culto da infância" (BOAS, 1990). Sobre a 
significação deste culto ele tem a sua origem no nascimento de Cristo em Belém que se prolonga ao longo da sua infância, sendo liturgicamente recordado no Natal onde se celebra a sua natividade. Além do costume do presépio perpetuar iconologicamente essa recordação, bem como a hagiografia cristã e católica ter-se igualmente encarregue de alimentar a vocação do Menino Jesus através dos tempos. Do ponto de vista mitológico, o Menino Jesus retoma o oximoro que caracteriza toda a simbólica mítica, a saber: uma criança que é simultaneamente a mais frágil e a mais forte, a mais humilde e a maior. Esta justaposição de contrários visa sugerir a transcendência divina. Aqui podemos dizer com Jean Hani que "o paradoxo antropológico conduz à compreensão do mistério teológico" (HANI, 1995, p. 263). Estamos assim perante simultaneamente a fragilidade de uma pobre Criança nascida num estábulo e a grandeza do Rei do Mundo.

Também é de notar a importância que o tema da criança ocupa na doutrina crística, fazendo inclusive desse tema a sua pedagogia de como entrar ou merecer o Reino dos Céus (MT 18, 1-4; LC 18, 17; MT 19, 14; MT 11, 5; Lc 10,21). Pensamos assim que Cristo atribui uma importância radical às virtudes próprias da infância que são as da humildade, da espontaneidade, da simplicidade e da inocência. São virtudes próprias do estádio primigênio, da inocência pura. Numa palavra, um estádio semelhante àquele que era conhecido antes da "Queda" e o qual novamente se recupera simbolicamente mediante o batismo. Na mundividência cristã, a infância não é considerada nem do ponto de vista social, nem psíquico, mas espiritual. Assim, a natureza da infância ultrapassa a sua natureza quer sensível, quer psicológica para se situar num plano eminentemente espiritual: a figura da Criança arquetipal reveste uma forma de Menino Jesus e ele é em nós atualizado quando um de nós realiza em si o milagre da Infância espiritual. Aliás, esta, segundo S. Paulo, não seria a via do cristão se transformar num "homem novo" que é o "homem perfeito, de acordo com a figura do Cristo na sua plenitude" (Eph. 4, 13). O "homem velho e maculado" morre simbolicamente para nascer uma segunda vez (um novo nascimento), enfim trata-se aqui de uma ressurreição espiritual!

Gilbert Bosetti, um estudioso da Criança Divina na literatura italiana do século XX, salienta que a Itália católica foi particularmente devota de Maria e do Menino Jesus. O tema da criança, enquanto objeto 
de adoração e de veneração, é portanto inseparável quer da infância do Menino Jesus (BOUFFARTIGUE, 1995, p. 241-258), quer do seu culto (HANI, 1995, p. 261-267) como, aliás, no início mencionamos. Uma devoção assumida por um culto transversal a todas as classes sociais, mas muito particularmente objeto de forte e ativa devoção e prática no seio das famílias mais humildes. Um culto que certamente levaria os mais humildes a redentarizarem-se pela procriação enquanto símbolo de uma esperança na renovação espiritual e num muito provável desejo de ascensão social. Assim, o nascimento de uma criança deixava de ser um acontecimento para se transformar numa chegada salvífica porque reatualizadora do nascimento crístico: "A vida de Jesus constitui um hipotexto incontornável de muitas narrativas que glorificam a criança, sobretudo após a I Guerra" (BOSETTI, 2002, p. 191). É neste contexto que devemos compreender a versão psicopedagógica da criança no pensamento educacional de Maria Montessori: uma versão laicizada, e que se pretendia científica, da criança sob forte influência da vida de Jesus. Tal não impede, que a autora, mesmo numa versão laicizada de valor ideo-metafórico, atribua às alusões e às citações explícitas da vida de Jesus um valor ontológico de alcance filosófico-pedagógico de grande densidade epistêmica.

Esta influência na obra de Montessori centra-se especialmente na cena da natividade de Jesus enquanto Deus redentor e não deixa de contaminar de forma patente a sua teoria e método psicopedagógicos. Por outras palavras, a pedagoga italiana abordou a criança numa perspetiva cientificizante, humanista e laica sem, contudo, a separar do nascimento e da infância de Cristo e do respetivo culto do Menino Jesus: "o recémnascido, nós não o escutamos: para nós, ainda não é um homem. Quando a criança vem ao mundo, no nosso mundo, nós não a sabemos receber, ainda que o mundo que criámos lhe esteja destinado, para que o continue e o faça caminhar para um progresso superior ao nosso" (MONTESSORI, s.d. [1936], p. 46). A criança aparece assim como a melhor garantia do progresso deste mundo que rejeite a guerra em prol da paz e do amor que tudo regenera e que aposta na formação de um "homem novo" que já o culminar de uma "criança nova": "Nós devemos acreditar na criança como se fosse um messias, como se fosse um salvador capaz de regenerar a raça humana e a sociedade" (MONTESSORI, 1996, p. 35). 
Se a abordagem da criança na obra de Montessori assenta numa descrição experimental do comportamento da criança (MONTESSORI, $2004^{\mathrm{ab}}$ ), tal não a impediu de atualizar, como vimos atrás, e de dar voz à Criança Divina, à Criança Redentora, enfim do Salvador Criança. É sob o signo do mitologema cristão da criança salvadora (BOSETTI, 1997, p. 101-126) que a abordagem teórica e sua prática psicopedagógica de Montessori se estrutura e se desenrola. Para melhor se compreender este fundo mitológico, importa salientar que Montessori nutre uma profunda devoção pela figura Menino Jesus enquanto Criança Divina. Por isso, compreende-se que ela compare a aventura do recém-nascido ao mistério da Encarnação na figura de Jesus menino:

Poder-se-ia comparar a vida do homem às três etapas da vida do Cristo: inicialmente o Menino, miraculoso e sublime, é a época da "sensibilidade criadora", da construção mental, tão intensa em actividades que é necessário nela depositar todas as sementes de cultura. Em seguida vem a época da adolescência: época das revelações interiores, das sensibilidades sociais. É a época onde o Cristo, adolescente, discutiu com os Doutores, esquecido da sua própria família (...); Enfim, vem o Homem que se prepara para a sua missão no mundo. E que faz ele para se preparar? Ele afronta o diabo e o vence (MONTESSORI, 1992, p. 165-166).

Em síntese, podemos afirmar que Montessori, voluntária ou involuntariamente, procura conferir à Criança Divina um sentido humano. Com esta afirmação, não pretendemos insinuar que a autora tenha feito da teologia cristã o seu ponto de partida para estudar o "segredo da infância", mas tão-somente sublinhar até que ponto a visão cristã da infância, nomeadamente o mitologema da criança redentora (correspondente aos pares junguianos "deus-criança" e "criança-herói"), marcou toda a sua obra: "Compreende-se facilmente que para uma alma religiosa, a criança possa aparecer como a inocência encarnada. A adoração da Criança Divina faz viver a alma que reza numa atmosfera de inocência primigénia" (BACHELARD, 1968, p. 113). 


\subsection{Para uma religião da infância}

Decorre do atrás exposto que a Criança Divina, projetada na figura do Menino Jesus, exerceu um fascínio intenso em Maria Montessori cuja obra, nomeadamente o seu Il segreto dell'infanzia (1938), reflete de um modo vivo e intenso. E por que não recordar que o Menino-Jesus aparece na lenda de São Cristóvão como aquele ser que é o "mais pequeno dos pequenos e o maior dos maiores". Esta ideia resume nela toda a orientação que a autora imprimirá às suas reflexões sobre a infância, não obstante o tratamento científico que faz do comportamento da criança. Os seus trabalhos estão contaminados por uma espécie de mitologia poética da infância como idade sagrada: a criança rei, a criança salvador, criança divina, a criança redentora são as designações correntes na sua obra psicopedagógica.

Porém, e antes de nos focalizarmos no caso Montessori, importa, a partir do próprio Gilbert Bosetti, traçar as linhas gerais daquilo que ele designou de religião da infância. Esta religião é constituída por todas aquelas narrativas impregnadas de religiosidade que ao sacralizarem a idade juvenil constitui para o autor "o verdadeiro mito de origem das sociedades ocidentais modernas" (BOSETTI, 1997, p. 143). A religião da infância encarada como um mito fundador exprime verdades psico-socioantropológicas que o autor restringe à cultura italiana, particularmente do período depois da I Guerra Mundial.

Do lado dos autores católicos, como é o caso de Maria Montessori, além da dimensão mítica enunciada, acresce igualmente a Verdade ontológica da Revelação, não impedindo que muitos desses autores também não considerem que a representação do divino seja de alguma forma uma idealização dos imagos parentais. Encontram-se, na sua obra, versões sociopsicológicas laicizadas dos principais acontecimentos da tradição cristã: Génesis e o tema da "Queda", a vida de Jesus com as cenas da Anunciação, da Natividade, da Adoração dos Magos, do massacre dos Inocentes, o regresso do Egito, de Jesus discutindo com os Doutores da Lei, a Crucificação e a Ascensão. Este retorno do religioso de cariz cristão no romance italiano contemporâneo muito contribui para a divinização da infância e sua mitologização: a criança exprime o começo e o fim, porque a morte é sempre um renascimento. Encontrando-se a Itália traumatizada 
e assombrada pela morte devido à Grande Guerra Mundial nada de mais natural e de mais humano que ela encontrasse na idealização da infância um reconforto especial. Deste modo, a criança, à semelhança do Menino Jesus, era encarada como a Criança divina, o anunciador da Boa Nova e o salvador que promete a ressurreição e sobrevivência da família: Esta temática renovou a busca da inocência, a reflexão sobre o mal, a interrogação sobre o nosso destino, a esperança de um mundo melhor" (BOSETTI, 1997, p. 147).

Gilbert Bosetti é o único autor, que nós tenhamos conhecimento, que tratando da obra psicopedagógica de Maria Montessori utiliza a expressão de religião da infância. Esta expressão cruza o registo científico, nomeadamente, o seu naturalismo evolucionista, e o registo apologético religioso cristão e católico: "Il segretto dell'infanzia é com efeito simultaneamente um tratado de psicopedagogia e uma profissão de fé, uma descrição experimental do comportamento da criança e uma mitologia poética desta idade sagrada" (BOSETTI, 1987, p. 44). O seu fundamento baseia-se na transferência explícita do amor de Jesus para criança "que nos ama e que nós deveríamos amar tanto como ela nos ama" (BOSETTI, 1987, p. 41-45). A criança traz com ela o amor em potência que, à semelhança do Cristo, se vê rejeitada e abandonada. O apelo da criança não é nem ouvido pela família, nem escutado pela sociedade e pela escola, Ninguém a sabe receber e assim a criança experiência um sentimento de abandono e de rejeição: "Ele veio ao mundo, /e o mundo foi criado para Ele/mas o Mundo não o reconheceu. /Veio à sua própria casa, /e os seus não o receberam", são as palavras de S. João Evangelista usadas pela autora para ilustrar a condição de carência em que a criança é deixada. Neste espírito Montessori usa igualmente a cena em que Cristo repreende aqueles que não souberam de modo algum reconhecê-lo no recém-nascido:

- Eu amei-te, eu vim despertar-te ao amanhecer e tu repeliste-me.

- Mas quando oh Senhor vieste à minha casa ao amanhecer para despertar-me e eu te repeli? - $\mathrm{O}$ fruto das tuas entranhas que veio chamar-te, era eu. Aquele que clamava de não o abandonar, era eu! - Insensatos! Era o Messias que vinha despertar-nos e ensinar-nos o amor! E nós que pensávamos que se tratava de um capricho infantil e é assim que se perdeu o nosso coração! (MONTESSORI, 1965, p. 142). 
Depois de a criança entrar na escola, "uma professora fecha a porta" tornando-se "dona e senhora, mandando naquele grupo de almas, sem testemunhas nem fiscalização" por parte da família e da Sociedade que confiam cegamente na autoridade da professora. Enfim, a escola "tem sido lugar de profundo desgosto", um Inferno onde a criança, tal como Cristo no Gólgota, passa "horas de agonia": "Olhares severos obrigam os pés e as mãozinhas a fincarem-se nos bancos com a mesma rigidez com que os cravos prenderam Cristo à cruz. E quando naquela mente, sedenta de saber e de verdade, se tiverem imposto as ideias do professor, que as introduz à força ou como melhor lhe parece, a pequena cabeça, humilhada pela sujeição, parecerá sangrar debaixo de uma coroa de espinhos" (MONTESSORI, s.d. [1936], p. 304-305). Esta analogia com a crucificação e Paixão de Cristo compreende-se melhor caso se perceba que o adulto ignora quem é a criança, bem como desconheça o "milagre que se está a realizar: o milagre da criação a partir do nada" (MONTESSORI, s.d., [1936], p. 74). Os pais, a sociedade e a escola são, segundo Maria Montessori, incapazes de utilizar construtivamente as "novas energias" que as crianças trazem naturalmente ao mundo, porquanto estas, para a trilogia pais-sociedade-escola, não passavam (ou não passam ainda!) de "extrasociais isoladas" (MONTESSORI, s.d. [1936], p. 295), desconhecendo que a criança, desde que nasce, luta pela sua presença no mundo e pelo desabrochar da sua vida psíquica. Paradoxalmente, a Sociedade virou as costas aos "pequenos operários a quem a Natureza confiou a missão de construir a Humanidade" (MONTESSORI, s.d. [1936], p. 295), ficando assim privados do seu mestre: a criança é o Mestre do próprio homem, pois não só contém o "segredo da nossa natureza", como é igualmente o "farol da nossa vida futura" (MONTESSORI, s.d. [1936], p. 290). Por isso mesmo, Montessori insiste que a tarefa principal da "educação nova" é "chegar primeiramente à descoberta da criança e realizar a sua libertação" (MONTESSORI, s.d. [1936], p. 155; MONTESSORI, s.d. [1949], p. 1820), pois só quando liberta a criança poderá realmente existir: "existir primeiramente", lê-se na obra A Criança (MONTESSORI, s.d. [1936], p. 155). E só existindo, quebrando o sepulcro, que a trilogia escola-sociedadefamília representa, que a criança, à semelhança de Cristo, pode finalmente libertar-se e ressuscitar: 
Ah! Aquele coração cheio de amor será trespassado pela incompreensão do Mundo, como por uma espada, e parecer-lhe-á amargo o que a cultura lhe oferece para apagar a sua sede. Está arranjado o sepulcro para a sua alma, que não pode viver com todos estes artifícios; e quando tiver sucumbido numerosos guardas vigiarão para que não ressuscite. Mas a criança ressuscita sempre e volve, fresca e risonha, a viver entre os homens (MONTESSORI, s.d. [1936], p. 305).

Mesmo não citando explicitamente o Evangelho, o transfundo da psicopedagogia montessoriana, o seu hipotexto ou palimpsesto, está imbuído das passagens da vida de Cristo, com especial destaque para a Natividade do humilde Menino que encarna o mistério da Encarnação, e, por conseguinte, a promessa da redenção, e a Paixão de Cristo. O que Montessori não deixa de lamentar é que a família não acolha o recémnascido com o fervor que ele merece, desconhecendo que ele é o enviado, o mediador da Boa Nova e do amor redentor: "Como o afirmou Emerson, a criança é o eterno Messias que sempre regressa entre os homens decaídos para os conduzir no Reino dos Céus" (MONTESSORI, 1965, p. 316).

A psicopedagogia de Montessori teórica e prática se procurou dar dela uma representação fundada numa pedagogia científica, que se pretendia inovadora, progressista e experimentalista (inclui aqui também a componente fisiológica), nunca deixou de afirmar-se também como um tipo literário contaminado pela tradição cristã e católica:

Eu não pretendo aqui apresentar um tratado de pedagogia científica; estas notas só têm como objetivo fazer conhecer os resultados de uma experiência que abriu uma via prática aos novos métodos. Estes métodos pretendem enriquecer a pedagogia de uma mais vasta utilização de experiências científicas, sem porém a separar dos princípios especulativos que constituem as suas bases naturais (MONTESSORI, 2004ㄹ, p. 9).

Num dos seus livros, de que Il segretto dell'infanzia é um exemplo, Maria Montessori desenvolve a sua argumentação num duplo registo: o científico e o apologético. Nessa obra, ela saúda a vinda do reino da Criança, dizendo que finalmente ela ocupa agora um lugar que lhe é de direito e todo 
o cuidado com ela é pouco, pois ela representa não só o "destino da nossa vida futura" (MONTESSORI, 1965, p. 291), como ela é o pai, o progenitor do homem (1965, p. 273; REGNI, 1997). Não é pois difícil constatar que quer ao nível patente, quer ao nível latente os escritos de Montessori estão imbuídos de uma atmosfera religiosa em que as referências à vida de Cristo são uma constante tanto ao nível metafórico, didático como ontológico:

Há com efeito em Montessori um mito da infância redentora que implica a escatologia e messianismo cristãos. Há em cada Filho do Homem um ideal potencial (à imagem de Deus) que o adulto trai, de modo que a criança nascida dele é ao mesmo tempo o seu remorso e a sua esperança de redenção. [...] É que a ideia da criança redentora é fundada nas esperanças pedagógicas concretas que são alimentadas pelos progressos da psicologia. A fé evangélica atribui uma dimensão mais poética que metafísica à confiança, à coragem e ao amor da educadora que não recuou diante os casos mais desesperados. [...] Assim, Maria Montessori passa da ciência da infância à religião da infância. Para ela, contribuir para o progresso da humanidade por uma educação ativa e amar a criança-deus segundo o ensino do Evangelho constituem um mesmo ato de fé no filho do homem. A psicopedagogia reativou a mitologia cristã do pequeno salvador (BOSETTI, 1987, p. 45).

Daí a autora insistir, na sua Educação e paz, que as crianças são simultaneamente "mestres da vida" e "mestres da paz" não somente ao nível da vida familiar como ao nível sociopolítico. Deste modo, elas são chamadas a desempenhar um papel crucial para evitar que a humanidade caminhe para a sua destruição e mergulhe novamente numa segunda guerra mundial o que infelizmente veio a acontecer, representando um duro revés no ideário da Educação Nova, muito especialmente nas expetativas e esperanças que Montessori depositava em evitar, por intermédio da nova educação e da "criança nova", um novo conflito bélico à escala mundial. Assim, Montessori esforça-se por chamar a nossa atenção para o facto de a criança, à semelhança do Messias, possuir todas as qualidades de um guia (MONTESSORI, 1996, p. 136-137 e p. 119), uma espécie de "condutor de almas" (um Hermes), capaz de conduzir os homens maculados para o reino dos Céus: a criança é mesmo comparada ao eterno Messias. 
Finalmente, Maria Montessori, em muitas passagens da sua obra, dedica uma particular atenção ao estado de abandono no qual a criança é deixada pela família, pela sociedade e pela escola: “A criança está no mundo como um exposto, quer dizer, como um abandonado; está sujeita a encontros obstrutores, inconscientes, mas todavia reais, de consequências fatais para a construção definitiva do indivíduo, a lutas pela existência psíquica" (MONTESSORI, s.d. [1936], p. 73-74); "Por isso se dá o drama social da criança: a Sociedade, insensível e quase sem qualquer responsabilidade, abandona a criança aos cuidados da família e esta, por sua vez, entrega-a à Sociedade, que a fecha numa escola" (MONTESSORI, s.d. [1936], p. 303) e "No limiar da porta, a família deixava-a [à criança] só, abandonada; e aquela porta era a defesa" (MONTESSORI, s.d. [1936], p. 304). Ora não é este estado de abandono da criança uma das características do arquétipo da criança? Não vimos anteriormente que Jung fez do abandono e da exposição aspetos significativos do arquétipo? A este respeito, o autor afirma: "O abandono, a exposição, o colocar em perigo, etc, pertencem, por um lado, ao desenvolvimento ulterior do início insignificante e, por outro lado, ao nascimento misterioso e miraculado" (MONTESSORI, 1974, p. 126).

Ligado ao tema do abandono infantil aparece o tema consonante da fragilidade da criança. No entanto, Montess ori não se revê na fragilidade clássica da criança contrapondo-lhe a capacidade dela regenerar-se e de afirmar-se como aquele ser possuidor de uma vida psíquica ativamente poderosa. Deste modo, a autora retoma, sem o saber, uma das caraterísticas principais do arquétipo da criança - o seu caráter invencível. Jung salienta que os mitos da infância caraterizam-se pelo seguinte paradoxo: "por um lado, a 'criança' acha-se exposta, sem defesa a inimigos extremamente poderosos, ela é constantemente ameaçada de destruição, e por outro lado, ela dispõe, pelo contrário, de forças que ultrapassam a medida humana" (JUNG, 1974, p. 130). Este paradoxo assinala a natureza divina da criança, pois só aparentemente é que ela é "insignificante" e esta questão não passou indiferente a Maria Montessori: "A criança não deve ser considerada como um ser frágil e impotente de que as únicas necessidades seriam de ser protegida e ajudada, mas como um embrião espiritual, possuindo uma vida psíquica ativa desde o dia do seu nascimento, guiada pelos instintos subtis que lhe permitem construir ativamente a sua personalidade humana" (JUNG, 1996, p. 61). 
A Criança Nova montessoriana, encarnando as características gerais que Jung assinalou em relação arquétipo da criança, como vimos anteriormente, aparece sob o signo de Hermes/Mercúrio e do Menino Jesus, respetivamente das tradições greco-romana e cristã. A "criança nova" montessoriana (MONTESSORI, 1931, p. 102-110) possui as qualidades de ambas as Crianças Divinas que são as seguintes: puer aeternus, mediador (leia-se: mensageiro), passado e o futuro, alto e baixo, guia" iniciador (DURAND, 1979, p. 280, p. 314-315). As qualidades referidas conferem realmente um sentido de "novidade" à criança, tornando-a uma criatura sempre "fresca e risonha", logo anunciadora de um "mundo novo" e de "homens novos".

\section{Referências}

ARAÚJO, A. F. Educação e imaginário. Da criança mítica às imagens da infância. Maia: Instituto Superior da Maia, 2004.

AVANZINI, A. Educazione nuova, scienze 'esatte' e pedagogia scientifica. Una rilettura del caso Montessori. In: ARAÚJO, A. F.; ARAÚJO, J. M. de. História, Educação e Imaginário. Actas do VII Colóquio de História, Educação e Imaginário (Universidade do Minho, 8 de Março de 2004). Braga: UM/IEP/ CIED, 2004, p. 141-155.

AVANZINI, G. L'Education nouvelle et ses concepts. In: HAMELINE, D. Jürgen H.; Jürgen O. (Dir.). L'Education Nouvelle et les Enjeux de son Histoire (Actes du colloque international des Archives Institut Jean-Jacques Rousseau: L'éducation nouvelle, au-delà de l'histoire hagiographique ou polémique, Genève, avril 1992). Bern: Peter Lang, 1995, p. 65-74

BACHELARD, G. La poétique de la rêverie. 6. éd. Paris: PUF, 1974.

BATTISTA, G. L'educazione religiosa in Maria Montessori. Milano: Massino, 1989.

BERNARD, M. Critique des fondements de L'education. Généalogie du pouvoir et/ou de l'impouvoir d'un discours. Paris: Chiron, 1988.

BERTINI, G. Il metodo Montessori. Firenze: Marzocco-Benporad, 1953. 
BIANCHI, B. Il sistema educativo de M. Montessori. Firenze: Le Monnier, 1952.

BLOCH, M. A. Philosophie de l'éducation nouvelle. Paris: PUF, 1973.

BOAS, G. The cult of chilhood. Dallas: Spring Publications, 1990.

BÖHM, W. Maria Montessori. In: HOUSSAYE, J. (Dir.). Quinze pédagogues. Leur influence aujourd'hui. Paris: Armand Colin, 1994. p. 155-157.

BOSETTI, G. Mythe et roman. Iris, n. 13, p. 83-98, 1993.

. L'enfant-dieu et le poète. Culte et poétiques de l'enfance dans le roman italien $d u X X^{e}$ siècle. Grenoble: Ellug, 1997.

. Le mythe de l'enfance dans le roman italien contemporain. Grenoble: Ellug, 1998.

. L'enfant divinisé. Sur le palimpseste de la vie de Jésus. Iris, n. 23, p. 191-202, 2002.

BOUFFARTIGUE, J. Les enfances de Jésus. In AUGER, D. (Dir.). Enfants et Enfances dans les Mythologies (Actes du VIIe colloque du Centre de Recherches Mythologiques de l'Université de Paris-X: Chantilly, 16-18 septembre 1992). Paris: Les Belles Lettres, 1995, p. 241-258.

CAILlOIS, R. O homem e o sagrado. Tradução de Geminiano Cascais Franco. Lisboa: edições 70, 1979 [1939 - L'Homme et le Sacré].

CALÓ, G. Maria Montessori. In CHATEAU, J. (Dir.). Os Grandes Pedagogos. Tradução de Maria Emília Ferros Moura. Lisboa: Livros do Brasil (Col. "Vida e Cultura"), s. d. [1956], p. 338-363.

COUSINET, R. A educação nova. 4. ed. Tradução de M. Emília Ferros Moura. Lisboa: Moraes editores, 1978 [1950 - L'Éducation nouvelle].

DUBUC, B. Maria Montessori: 1'enfant et son éducation. In: GAUTHIER, C.; TARDIF, M. (Dir.). La pédagogie. Théories et pratiques de l'antiquité à nos jours. Montréal: Gaëtan Morin Éditeur, 1996, p. 157-175.

DURAND, G. Figures mythiques et visages de l'Oeuvre. De la mythocritique à la mythanalyse. Paris: Berg International, 1979.

. A Imaginação simbólica. Tradução de Maria de Fátima Morna.

Lisboa: Arcádia, 1979. [1964 - L’imagination symbolique] 
. O homem religioso e os seus símbolos. In: . Portugal.

Tesouro oculto da Europa. Tradução de Lurdes Feio. Lisboa: Ésquilo, 2008, p. 219-272.

ELIADE, M. O sagrado e o profano. A essência das religiões. Tradução de Rogério Fernandes. Lisboa: Livros do Brasil, s.d. [1959 - The Sacred and the Profane]

GRÁCIO, R. Maria Montessori. In: Lisboa: Livros Horizonte, s.d., p. 171-181, 1973.

Educação e educadores. 2. ed.

HAMELINE, D. Courants et contre-courants dans la pédagogie contemporaine. Paris: ESF, 2000.

HANI, J. Le culte de l'enfant-Jésus et sa signification. In: AUGER, D. (Dir. Enfants et Enfances dans les Mythologies (Actes du VIIe colloque du Centre de Recherches Mythologiques de l'Université de Paris-X: Chantilly, 16-18 septembre 1992). Paris: Les Belles Lettres, 1995, p. 261-267.

JOLBERT, B. Raison et Education. Paris: Éditions Klincksieck, 1987.

JUNG, C. G. (1974). Contribution à la psychologie de L'Archétype de L'Enfant. In: JUNG, C. G.; KERÉNYI, C. Introduction à L'Essence de la Mythologie. Traduçao de H. E. Del Medico. Paris: Payot [PBP], 1974, p. 105-144.

KERÉNYI, C. L'Enfant Divin. In: JUNG, C. G.; Kerényi, C. Introduction à L'Essence de la Mythologie. Tradução de H. E. Del Medico. Paris: Payot [PBP], 1974, p. 43-104.

KILPATRICK, W. The Montessori system examined. Boston: Houghton Mifflin, 1914.

KRAMER, R. Maria Montessori. Chicago: University of Chicago Press, 1976.

LEONARDUZZI, A. Maria Montessori: il pensiero e l'opera. Brescia: Paideia, 1967.

LILLARD, P. P. Montessori. A modern approach. New York: Schocken Books, 1972.

MIALARET, G. Éducation nouvelle et Monde Moderne. 2. ed. Paris: PUF, 1969. 
MÉDICI, A. A educação nova. Tradução de Natércia Barros. Porto: Rés, 1976.

MEIRIEU, P. Maria Montessori. Peut-on apprendre à être autonome?. Paris: Éditions PEMF, 2001.

MONTESSORI, M. L'Enfant nouveau. La Nouvelle Éducation, Paris, n. 96, junho, 1931. p. 102-110.

. Il segretto dell 'infanzia. Milano: Garzanti, 1965 [1936-L'Enfant]. . A criança. Lisboa: Portugália Editora, s.d. [1936 - L’Enfant].

- Formação do homem. 3. ed. Tradução de Eunice Arroxelas.

Lisboa: Portugália Editora, s.d. [1949 - Formazione dell'uomo].

. I bambini viventi nella chiesa. La vita in Cristo. La Santa Messa.

Milan: Garzanti, 1970 [1922, 1931 (datas originais em italiano), 1932 (Mass Explained to Children)].

. A mente da criança (Mente Absorvente). Tradução de Pedro da Silveira. Lisboa: Portugália Editora, 1971 [1949 - The absorbente mind]. . De l'enfant à l'adolescent. Tradução de Georgette J.-J. Bernard. Paris: Desclée de Brouwer, 1992 [1948 - edição francesa original]. . L'éducation et la paix. Tradução de par Michel Valois. Paris, 1996 [1949 - Educazione e Pace].

. Educazione per un mondo nuovo. Tradução de Maria Attardo Magrini. Milano: Garzanti, 2000 [1947 - Education for a new world].

. Éduquer le potentiel humain. Paris: Desclée de Brouwer, 2003 [1947 - To educate the human potential].

. Pédagogie scientifique. T. 1 - La maison des enfants. Tradução de Georgette J.-J. Bernard. Paris: Desclée de Brouwer, 2004ª [1909 - Il metodo della pedagogia scientifica applicato all'educazione infantile nelle Case dei Bambini].

. Pédagogie scientifique. T. 2 -Éducation élémentaire. Tradução de Georgette J.-J. Bernard. Paris: Desclée de Brouwer, 2004 ${ }^{\mathrm{b}}[1914-D r$. Montessori's Own Handbook].

. Éducation pour un monde nouveau. Tradução de Jacqueline Oudin. Paris: Desclée de Brouwer, 2010 [1947 - Education for a new world]. 
NÓVOA, António. Uma educação que se diz «nova». In: CANDEIAS, A. et al. Sobre a educação nova. Cartas de Adolfo Lima a Álvaro Viana de Lemos (1923-1941). Lisboa: Educa, 1995, p. 25-34.

. Regards Nouveaux sur l'Éducation Nouvelle. In: CHARBONNEL, N. (Textes réunis). Le Don de la Parole. Mélanges offerts à Daniel Hameline pour son soixante-cinquième anniversaire. Berne: Peter Lang, 1997, p. 71-96.

OHAYON, A.; Dominique Ottavi \& Antoine Savoye (Ed.). L'éducation nouvelle, histoire, présence et devenir. Berne : Peter Lang, 2004.

PERETTI, M. Il metodo Montessori: presentazione e valutazione critica. Treviso: Canova, 1952.

OTTO, R. Le Sacré. L'élément non rationnel dans l'idée du divin et sa relation avec le rationnel. Tradução de André Jundt. Paris: Petite Bibliothèque Payot, 1969.

REBOUL, Olivier. La Philosophie de L'Éducation. 2. Ed. Paris: PUF, 1990.

. Les valeurs et l'Éducation. In JACOB, A. (Dir.). Encycopédie Philosophique Universelle. I. L'Univers Philosophique. 2.ed. Paris: PUF, p. 197-202.

. Les valeurs de l'éducation. Paris: PUF, 1992.

REGNI, R. Il bambino padre dell'uomo. Infanzia e società in Maria Montessori. Roma: Armando, 2007.

RICEUR, P. Philosophie de la volonté. II. Finitude et culpabilité. Paris: Aubier, 2002.

RÖHRS, H. Maria Montessori (1870-1952). Perspectives: revue trimestrielle d'éducation comparée, vol. XXIV, n. 1-2, 1994, p. 173-188.

SARTOR, R. F. Maria Montessori. Brescia: La Scuola, 1961.

SERVIER, J. L'Homme et L'Invisible. Monaco: Éditions du Rocher, 1994. SIRONNEAU, J.- P. Idéologie et mythe. In CHAUVIN, D.; Siganos, A.; Walter, P. (Dir.). Questions de mythocritique. Dictionnaire. Paris: Imago, 2005, p. 183-192.

SNYDERS, G. Pédagogie progressiste. Éducation traditionnelle et éducation nouvelle. Paris: PUF, 1975. 
STANDING, E. M. Marie Montessori. Sa vie, son æuuvre. Paris: Desclée de Brouwer, 1995.

VALITUTTI, S. Il problema dell'educazione nel pensiero di Maria Montessori. Ed. Vita dell'Infanzia: Roma, 1953.

WALTER, P. Avant-propos. Iris, n. 23, 2002, p. 3-6.

WUNENBURGER, J.-J. Le Sacré. 6. éd. Paris: PUF, 2009.

YAGLIS, D. Maria Montessori. Paris: Éditions Privat, 1984.

Data de registro: $22 / 03 / 2013$

Data de aceite: $21 / 08 / 2013$ 